\title{
Crossing Borders: Trends in Operations and Global Supply Chain Management
}

\author{
Henrique Corrêa \\ Crummer Graduate School of Business, Rollins College, Winter Park, Fl, USA
}

\begin{abstract}
The management of global supply chains and the impact of 3BL do not represent a rupture but rather another stage of evolution in the expansion of scope that the area of operations management has been experiencing since the beginning of the 20th Century. It is a fact, however, that the current stage of evolution is occurring in a more accelerated rate than in previous stages and it is also a fact that the levels of volatility, complexity and social pressure on supply chains today and in the future do not have historical precedence. This is one of the reasons why logistics and supply chains will continue to be important factors of differentiation in the market for a long time in the future. But what are the future tendencies for the management of supply chains and how should managers prepare themselves for these tendencies? The goal of this article is to briefly revisit the history of the field and then explore these questions.
\end{abstract}

Keywords: Global supply chain management, Operations management, Evolution, Triple bottom line, Uncertainty, Complexity, Volatility.

\section{Introduction}

The creation of economic activity zones like APEC, ASEAN, EU, NAFTA and MERCOSUL and the relaxation of commercial laws and tariff structures through organisms such as GATT have helped to create a "global marketplace". Today it is not uncommon to find companies that develop their products in one country, manufacture it in another one from supplies sourced from all around the world and to sell it in a third. Products are now launched in a range of countries almost simultaneously and suppliers, with knowledge and specific technology, collaborate with manufacturing firms to create global products. As the world moves towards a globalized economy, what firms most aspire for and need is to make their operations truly global. As long as globalization promises great strategic benefits through the coordination of localized operations in diverse countries, it is essential that managers understand and explore the intricate mechanisms of the current and future global market. Managing manufacturing and/or service operations that cross borders between firms, regions and countries with diverse cultures, economies, rules $\&$ regulations and, politics is a great challenge, which is the reason why many companies have not succeeded in their globalization efforts.

Even companies that have learned to substantially reduce the inefficiency of their internal operating systems (whether they be factories or service units) through concepts such as just-in-time, process control, lean and six sigma, still experience 
difficulties in making the required physical and informational flows pass through the various steps of their global supply chains in an effective way in terms of customer service, with low economic, social and environmental cost. This is one of the reasons why logistics and supply chains will continue to be important factors of differentiation in the market for a long time in the future. But what are the future tendencies for the management of supply chains and how should managers prepare themselves for these tendencies? The goal of this article is to explore these questions.

\section{Historical Evolution of Supply Chain Management}

Knowing the past helps us to understand the present and be better prepared to confront the future. Keeping this in mind, we will briefly revisit the most recent evolution in the broader area in which supply chain management is: operations management.

\section{First phase: the scope of operation management is restricted to the plant - there is "one best way" of operating}

We will start our historical 'tour' at the beginning of the 20th Century. At the turn of the 20th Century, the work of the steel industry consultant Frederick Taylor (Taylor, 1911) resulted in the appearance of "Scientific Management", one of the first manifestations of the use of the analytical paradigm to manage the execution of tasks. The principles of Scientific Management include the allocation of tasks to the workers most able to carry them out, the division of tasks into sub-tasks rendering them more easily analyzable, the separation of analysis \& development of the production method and its execution and, the use of a set of well-defined rules in the sense of trying to eliminate any form of waste in the performance of the task. Taylor (1911) believed that if his principles were diligently applied for improvement of the method used to realize tasks then this process would come together as the "one best way" of realizing them.

The industrialist Henry Ford used the logic of Scientific Management extensively and added improvements (for example the creation of the moving assembly line in 1913) which would permit Ford Motor Co. to become the greatest car manufacturer in less than 20 years. In these 20 years, the cost of a Ford car fell from a few thousand dollars to a few hundred dollars (Tedlow, 2001), enabling a vast quantity of people with less purchasing power, and thereby sensitive to "price", to purchase a car, which was hitherto the privilege of the few.

Nonetheless, this incredible rise in production efficiency was obtained with the sacrifice of the variety of products. Ford was inspired by a very cheap product, a pin, which he used to develop his strategy. According to him, the "secret" of the low cost of pins was that they were produced in massive quantities and were all identical. Ford therefore created his own "pin": Ford Model "T". It is common for people to say that back then, the consumer could have had any Ford car, in any color - as long as it was a black Model "T" - they were all the same and produced in massive quantities. By comparison, Brazil has beaten records in the annual production of vehicles, standing today as one of the 5 greatest producers in the world. Almost 20 assemblers, almost 40 manufacturing plants established in Brazil, have produced around 3.4 million cars and commercial vehicles in the year 2011 (Anfavea, 2012, p. 58). Impressive. Well, it's not that much if we consider that Ford alone, with only two manufacturing plants in 1923, produced more than 2 million Model "T" cars (Tedlow, 2001). 
With Ford Motor Co. as a main model, various products have been produced en masse. The production of Ford, just like various other mass-producers of the time, was extremely vertically integrated. This means that most tasks were internally executed by the company. The level of outsourcing was very low. The management of operations was greatly influenced by the mass production paradigm. The idea that there was "one best way" of performing tasks and that efficiency should be sought through economies of scale dominated for a long time. This paradigm did not demand that operations management and its methods crossed any frontier at all: if sufficient effort was made, focusing exclusively upon the production unit itself, the "one best way" of performing tasks would be met and therefore, successful on the extremely cost-conscious market.

\section{The second phase: operations cross functional borders - trade-offs are recognized}

Nevertheless, markets ripened. Various countries saw their populations become more affluent and their markets became more sophisticated and demanding throughout the first decades of the 20th Century. Some market segments were even willing to pay more for products as long as these offered better performance in another way such as having better quality, more alternatives to choose from, characteristics that better met customers' individual needs, faster delivery, higher customization levels and the like.

Alongside this came a better understanding of the multidimensionality of performance of operations (one could compete in more than one aspect of performance). With multidimensionality came a better understanding of the relationships between various dimensions for example, the fact that some pairs of dimensions would represent conflict (trade-off) to each other (Skinner, 1974), at least in the short-term, in other words, in certain situations it would be necessary to compromise the maximal performance of one dimension to maximize the performance of another. It was clear that in this "new world" there was not "one best way" of executing operations tasks.

The implication of this was that operations managers understood that it would be necessary to "cross the functional border" between the operations function and the marketing function for a better understanding of what the precise composition of necessary characteristics is for performance (cost, quality, delivery, flexibility and service) in order to compete in the target markets of the organization (Hill, 1985; Skinner, 1969). This is because, in order to maximize the performance of delivery speed for example, it may be necessary to compromise minimum cost. Think about an operation, for example, firemen. They deal with great uncertainty of demand associated with the necessity of quick attendance. In this case, the firemen are forced to work with very low levels of equipment utilization rates. The trucks are idle most of the time but they need to be prompt whenever a fire occurs, thus working far from the point of "minimum" cost.

To deal with the enhanced scope of operations and with the needed continuous harmonization between operations and the market, the sub-field of operations strategy (Skinner, 1969; Hayes and Wheelwright, 1984) was created and developed in the last third of the 20th Century (for details consult also Corrêa and Corrêa, 2012). Also in the second half of the 20th Century, the world of operations management realized two facts: the first is that a company finds it difficult to offer their clients either service or physical goods alone, but in most cases, they offer a value package which contains 
elements of both (Corrêa et al., 2007). The second is that the services are responsible for greater and greater parcels of the GDP of countries in so far as they are walking the path of development. In Brazil, for example, services represent more than $50 \%$ of the GDP, in the U.S. more than $70 \%$ of the GDP and in Scandinavian countries more than $80 \%$ of the GDP. This implies that the management of operations must look at the necessary operations to create the "service" part of the value packages offered by the companies to their clients, no matter how great their percentage of participation in the package (Johnston, 1994).

Service operations are known for having a much less clear separation between operations, marketing and human resources (HR) than in manufacturing (Corrêa and Caon, 2002). Think about a restaurant manager and try to define the function that $\mathrm{s} / \mathrm{he}$ holds. You will find it difficult because s/he manages aspects of marketing as much as operations as much as HR. This forced operations managers to cross other functional borders - such as with HR and product development, broadening yet again the scope of its performance. It became more important to integrate analysis and decision processes in an expanded scope, still within the organization, between various functions with often conflicting interests and thus more complex trade-offs to be managed.

\section{Third phase: operations cross borders between organizations - supply chains}

Also, throughout the 20th Century, technological development accelerated at a rate hitherto unheard of (Utterback, 1994). The products increased greatly in terms of complexity. Think about a vehicle and about how many different and complex technologies are involved: motorization, suspension, breaks, safety, internal comfort, maintenance, structure, painting, among many others. Companies started to find it very difficult to keep up with the development of all the technologies involved in their products. To avoid running the risk of trying to be excellent in everything and ending up being mediocre in everything, companies increasingly began to delegate to specialized suppliers, first the manufacturing and then also the conception and design of increasing portions of their products (Gottfredson et al., 2005). The so-called outsourcing, while intensifying, forced operations managers to adapt and learn to cross another border, the border between organizations in what is now called "supply chains" (Corrêa, 2010). The scope widens yet again, the trade-offs become more complex and the necessary integration between internal decision processes of each company that is part of the chain demands more complex management. The alignment of incentives (Narayanan and Raman, 2004) between companies with diverse property ownership is something, for example, that becomes mandatory and with which the operations managers, now called supply chain managers, were not used to and many times weren't prepared for. They had to reinvent themselves, nonetheless, and learn and adapt themselves to the new reality.

\section{Fourth phase: operations cross national borders - global supply chains}

But towards the end of the 20th Century, the technological developments in telecommunications and transportation, asides from the globalizing initiatives of governments (reduction of trade tariffs and barriers and other initiatives that made international commerce grow exponentially) made it viable for companies to seek 
suppliers and other commercial partners wherever they were located in the world (Trent and Monczka, 2005). Supply chains became "global supply chains". The scope of activities to be managed by operations managers now expanded to a worldwide scale and the management of trade-offs became yet more complex. New elements started to integrate the decision-making scope of managers: time-zone differences, working standards, languages, culture, ethical standards, management systems and practices, among many others. These differences brought growing complexity to the necessary integration between the decision-making processes of partners in these global networks. Operations managers more than ever needed to become masters in the art of managing complex trade-offs.

\section{Fifth phase: operations cross borders of the organization global objective - the triple bottom line}

By the beginning of the 21st Century, a substantial change begins to take shape. Until the $90 \mathrm{~s}$, the management of complex supply chains with greater scope aimed, almost exclusively for the economic prosperity of its members. The masters of trade-offs, global supply chain managers, tried to balance various conflicts aiming to increase the economic value of the chains and its members. However, a new widening of scope was occurring. Encouraged by the advent of connectivity made possible by the internet and its instruments, other interest groups began to have a growing influence on the management of global supply chains: organized society, like NGOs and government bodies, in the name of citizens, started to demand that corporations and supply chains begin to assume increasing responsibility for environmental sustainability of the planet and for its social impact. The term "triple bottom line" (3BL) (term coined by Elkington, 1997) came into being, in a reference to the last line of traditional financial statements that represented profit: The triple bottom line refers to 1) Economic prosperity, 2) Environmental sustainability and, 3) Social responsibility.

Once more, the managers of global supply chains had their current scope amplified, with the crossing of yet another border, the border of corporate performance objectives: it is not only profit that matters but also the planet and people. Trade-offs became even more complex. For example, if previously it was necessary to balance the decision between which supplier to use considering trade-offs between price, reliability, speed, quality, flexibility and service, now there was a growth in other aspects of performance, for e.g., how much the supplier pollutes (what is its "carbon footprint"), how much solid residue he sends to a landfill, how much he uses water, how he contributes to the communities where he is located, etc. In other words, it was already difficult to decide how much one would be willing to pay for instance for a speedier delivery. Now on top of that type of trade-off one has to decide for instance how much s/he would be willing to wait (or pay more) for a delivery that generates less carbon or that contributes more towards the community. Yet again, the operations and supply chain manager witnesses his scope of action amplified. The trade-offs to be managed become more complex, there is greater complexity in the integration of decision-making processes involved with the constituents of the chains with expanded scope and this is the situation that we are facing today.

We will now try and identify some related future tendencies of the management of global supply chains. 


\section{Relevant Trends for the Management of Global Supply Chains}

It seems that a number of aspects will have a particularly relevant influence on the global supply chains and their management in the future. We will analyze a few of these.

\section{Increase in Volatility}

With the global supply chains crossing more and more borders, alongside the growing necessity of integration of decision-making processes, the chains are more and more interconnected and their members are more and more interdependent in that an alteration in an individual part of the chain has an influence on practically all the other parts. The possibility of a catastrophic interruption in one or more links of the chain is a constant source of concern for managers today. The worry is not only concerning random natural phenomena like tsunamis, floods or earthquakes rendering plants or other facilities inoperative (as happened in March 2011 in Japan, with a tsunami having an impact on various industrial sectors of the world). Numerous other factors have caused substantial disruptions with a global panorama: strikes, sabotage, terrorism, exchange rate and commodity price fluctuations, fluctuation in fuel prices, economic crises affecting the demand in certain regions, besides the entry of billions of people into the consumer's market, with the expansion of emerging countries causing a boom and placing great pressure on natural resources. The result is a greater and growing volatility tendency in environments where global supply chains operate. Executives agree. In a recent 2010 study of the consulting company McKinsey, with executives from large companies, $68 \%$ of them consider that the risks of their supply chain rupture are going to increase in the next 5 years (McKinsey, 2012).

\section{Increase in Complexity}

Supply chains have had to deal with a diversification and customization of products hitherto unheard of. According to Mik et al. (2011), the manufacturers of cell phones launched 900 models more in 2009 than they had launched in the year 2000, when cell phones were already an established technology. The number of different products like drinks, cereal and confectionery experienced an increase of more than $25 \%$ between 2004 and 2006 .

On the other hand, the emergence of developing countries has created a massive number of middle-class consumers making these consumer markets highly attractive to both domestic and multinational companies. However, the distribution of products in developing countries has great challenges like absence, engulfment/ bottlenecking or bad quality of the infrastructure of transportation and communication, difficulty of access to large sections of the population living in remote or non-urbanized regions (some even without formal addresses) and inexistent or embryonic distribution structures (as is the case in India and China). This substantially increases the complexity and uncertainty of the global supply chains that serve these markets (Dobberstein et al., 2005)

Another aspect that has contributed to the complexity of global supply chains is the tendency for increase in commercial "returns" and manufacturer's "recalls" requiring the development of complex solutions for the so called reverse supply chains 
(Blackburn et al., 2004). The reason for an increase in returns is related to two factors: the first concerns the fact that markets are becoming more competitive and the policy of "no questions asked" for returns tends to be adopted as a competitive differential or, as it is in the US, a "qualifying" condition. In the U.S., around 6\% of products sold by big retail stores such as Wal-Mart, Target and Costco are returned for a great variety of reasons. In Europe, this percentage falls to around 1\% and in Brazil the percentage is even lower, but the tendency is for growth. The second factor is the growth of e-tailing (internet business-to-consumer commerce). Today, products such as shoes and clothes are increasingly bought on the internet. As they are products that are intended to serve the dimensions of the body of the clients, these models of business receive returns that can reach up to $50 \%$ of the products sold.

\section{Increase in the Influence of Organized Society and Governments to Make Organizations Pursue the "3BL"}

It has become clearer to society as it has to everyone that profit should not be the only defining element of success in companies and economies. It is also important to consider the future of people (internal and external to the organization in focus) and the planet. These concerns have increased recently because countries such as Brazil, Russia, India, China (those called BRIC countries, great economies experiencing accelerated growth) and others have grown at unprecedented rates thus causing drastic increases in the rate of consumption of natural resources demanded to meet the needs and desires of their consumers. Furthermore, there are other potentially harmful impacts of the current model of fast economic growth: on the one hand, to meet the energy and other production resource needs for accelerated growth, the world has generated growing quantities of polluting emissions which have not only harmed the quality of the air, water, and ground, but, as scientists argue, they have also been responsible for global warming.

On the other hand, the disposition of products, wrappings and other materials after their use has filled the landfills at an unprecedented rate that is no doubt unsustainable in the long-term. To counter this, society has organized itself and the tendency is for pressure to be put on companies so that they alter their processes and even their business models to conform to a greater concern with environmental sustainability and social responsibility. Further to this, actions in production processes also have implications for supply chains. The pressure to reduce the generation of residues calls for an increase in re-use and recycling. The management of reverse supply chains needed to deal with re-use and recycling will be crucial for the supply chains of the future.

Some analysts believe that as long as societies, through their pressure mechanisms, force companies to incur the real cost of their production processes there will be a substantial change in the configuration of global supply chains. An example is the price of fuel. Although not currently low, it doesn't include any charges or taxes referring to the environmental damage caused by its extraction, transport and burning. If/ when governments start to charge fuel-consuming companies for these damages in the form of charges or taxes, it is expected that the price of fuel will multiply thereby rendering, for example, global sourcing less viable, as it depends on transcontinental transport, a recognized big fuel consumer. If this happens, in the medium to long-term 
we can expect a reversal in global sourcing with a possible tendency for re-insourcing and near-sourcing with a return to more intensive use of local or near suppliers and, therefore, the breaking of global supply chains into more "regional" supply chains. This would have the side effect of reducing, up to a certain point, the complexity that is found in global chains today.

\section{Necessary Competencies for the Management of Supply Chains in the Future}

Considering the three tendencies identified above, some competences seem to be relevant for the management of future supply chains.

\section{Competencies to Deal with the Rise in Supply Chain Volatility}

To deal with the expected rise in volatility, it is important that supply chains develop competencies pertinent to risk management. Not only risk management associated with traditional accidental disruption factors (such as defects, delays and suppliers leaving the market) and random (such as natural phenomena), but also less obvious risk factors such as fluctuations in the price of commodities and fuel, the financial situation of suppliers and consumers and ethical and legal questions concerning members of the chain (Sheffi, 2005). In general, the mechanisms of risk management require some form of method to evaluate the probability of the occurrence of a risk factor and some form of evaluating the impact of its occurrence considered simultaneously to define which priority actions should be adopted to reduce the probability of the chain being affected by the risk factor and/or to reduce the negative consequences for the chain, in case the factor manifests itself (for details, see Corrêa, 2010).

Among the necessary competencies to mitigate the probability of the occurrence of risk factors are: 1) Intelligence in terms of monitoring and forecasting concerning risk factors; 2) Coordination and integration of decision-making processes with chain partners; 3) Confinement of risk factors to avoid "contamination" of the chain; 4) Risk mitigation, through mechanisms such as flexibility and redundancy of resources in terms of stock, capacity, TI systems; and, 5) Proactive maintenance and training.

Among the necessary competencies to reduce the impact of risk factors are: 1) Continual monitoring of critical factors; 2) Flexibility and redundancy of resources in terms of stock, capacity and systems; 3) Increased interchangeability and standardization in terms of parts, methods and equipment, multi-skilled people and flexible plants; 4) Postponement and parallelization of operations; 5) Agility of communication, a culture focused on security, proactivity and autonomy for rapid response to occurrences.

See Sheffi (2005) for more discussion on this important theme.

\section{Competencies to Deal with the Increase in Supply Chain Complexity}

To deal with the expected increase in complexity it is important that the chains develop competencies related to the ability of managing and adopting innovative solutions, as the levels of complexity today and of the future are unprecedented. Obviously it is always advisable, before dealing with levels of increased complexity, to question if it is not possible to reduce said complexity. For example, the enormous 
diversity of products, assumed as necessary in some companies, may be seen as counterproductive in the eyes of the client (some clients can feel put off when the number of options becomes excessive and some give up buying). However, for many industries, the increase in product variety appears inevitable and to deal with it, some additional competencies may be useful. They are discussed below.

To generate innovative solutions for complexity, the ability to monitor the environment and learn from it is essential, for example, with mechanisms such as functional benchmarking, in which one systematically seeks to learn from best practices adopted by world class companies, not from the same industrial sector, but from outside the industrial sector. For example, a company with pharmaceutical products (OTC, or over the counter) seeking to attack a new market without well-established distribution structures may learn with the operation of Avon Cosmetics in the Brazilian Northern region www.avon.com.br. A traditional retail company of electronics products that sees its levels of commercial returns increasing may learn reverse logistics practices from Zappo's www.zappos.com, a retail company of shoes and other products on the internet that has been dealing with high levels of commercial returns since the company's inception.

To deal with complexity in terms of proliferation of products it is important to develop competencies related to the use of postponement. Postponement relates to delaying the definition of the final product until, where possible, after the order of the client has been received. A good example can be the supply chains that sell wall paint today; they wait for the order of a client in the retail store to come in before mixing the 12 or so basic standard colors and by doing so, they are able to transform them into millions of possible final products. This involves innovative forms of designing products, of producing them and of allocating production activities to the various parties involved in the chain. In some situations it will be necessary to completely redesign the chain but this, strategically, may be worth it.

Another crucial skill to deal with increased levels of complexity is related to the ability to integrate decision-making processes in the chain (by increasing information sharing and decision-making coordination levels) and aligning incentives within the chain. For this, in general, high levels of trust are necessary, which one can achieve with: 1) Decisions of outsourcing that observe the strategic implications about when to outsource and when to internally produce, and by doing so "distributing" the complexity between partners; 2) The careful choice of key-partners in the chain to whom activities are outsourced, considering multiple aspects that obviously include supplier location; 3) the establishment of long-lasting relations with the key-partners with whom the sharing of information and the integration of the process of decision-making are intensified; 4) the development of contractual forms and of relationships with partners in the chain that better distribute risks and returns, in such a way that incentives of the chain partners are aligned (for details, see Corrêa, 2010).

Finally, one last skill worth mentioning concerning dealing with complexity is related to operational focus. Trade-offs discussed in the initial section of this article are obviously manifested in supply chains. The use of the same supply chain structure (the same logistics footprint - plants and warehouses, the same structure of transport) to produce and distribute products that compete in very different ways in the market can cause an unnecessary increase in complexity for the chain. The segmentation of 
the supply chain of a company based upon characteristics of the products they produce and distribute can not only increase the operational focus as it can reduce complexity. Fisher (1997) for example, suggests that innovative products (products with more unpredictable demand, shorter life cycles and frequent product launches) should be served by responsive (agile and flexible even if less efficient) chains while functional products (products with more stable demand, longer life cycles and less frequent product launches) should be attended to by efficient chains (even if less flexible and responsive). If a company has both innovative and functional products, according to this logic, it should be able to segment them accordingly and allocate each of them to be produced and distributed by two separated less complex and focused supply chains, that is one responsive, and the other one, efficient.

\section{Competencies to Deal with the Increase in Pressure for 3BL}

One skill that may be important in dealing with the increase in internal and external pressure for 3BL objectives is that of seeking, developing and maintaining productive and collaborative partnerships with key-pressure groups, such as NGOs and government bodies. Partnership and collaboration with NGOs such as Greenpeace, for example, in some instances has proved to be more effective than confrontation. MacDonald's www.mcdonalds.com is a company that has adopted this approach having dealt with boycotts and accusations (of indirectly causing deforestation) very well, working in partnership with Greenpeace www.greepeace.org itself and other NGOs, as much from a point of view of effectively resolving the problems as much as from that of public relations (Goldberg and Yagan, 2007).

Another useful competency in terms of guaranteeing required levels of social responsibility not only of the company in focus but also that of partners in the chain is the mapping out and management of related risk factors, for example, of partners possibly using child labor, inhumane working conditions, among others throughout the chain. This should include not only direct suppliers but also suppliers' suppliers and so on.

Finally, a skill set that is increasingly becoming useful in terms of operations contributing to improved environmental sustainability is related to the "lean" thinking (Womack and Jones, 2003). Companies of considerable performance in terms of the reduction or its environmental footprint (as for example the Subaru www.subaru.com plant in the state of Indiana, USA that is proud of having reduced its residues sent to landfills to ZERO through the systematic application of the Reduce-Reuse-Recycle principles) have become masters in the use of "lean" principles but taken to the extreme. The goals are the same: reduce waste and continuous improvement. The unnecessary use of resources, generation of emissions, waste and solid residue are nothing more than waste and the use of "lean" principles taken to the extreme can help chains to achieve better levels of environmental sustainability.

\section{Final Considerations}

The management of global supply chains and the impact of 3BL do not represent a rupture but rather another stage of evolution in the expansion of scope that the area of operations management has been experiencing since the beginning of the 20th Century. This is important because, as it is an incremental process, this evolution does not require, strictly speaking, a totally new set of solutions, but rather many of 
the solutions developed historically in other stages of this expansion can be used (and/ or adapted) to meet current and future needs. It is a fact, however, that this evolution is occurring in a more accelerated form than in previous phases and it is also a fact that the levels of volatility, complexity and social pressure on supply chains today and in the future do not have historical precedence, requiring all the competencies required in the previous phases of evolution and some additional ones. It is important that companies are conscious of what these are for their specific environment and that they get prepared, arming themselves with them, to face a challenging future.

\section{References}

Blackburn, J.; Guide Junior, V.D.R.; Souza, G.C. and Van Wassenhove, L.N. (2004) Reverse Supply Chains for Commercial Returns. California Management Review, Vol. 46. No 4. Winter

Brazilian Automotive Industry Yearbook - ANFAVEA. (2012) Available: http://www. virapagina.com.br/anfavea2012/ Access: 16th October 2012.

Corrêa, H.L. and Caon, M. (2002) Gestão de serviços. São Paulo: Atlas.

Corrêa, H.L. and Corrêa, C.A. (2012) Administração de Produção e Operações. 3rd ed. São Paulo: Atlas.

Corrêa, H.L. (2010) Gestão de Redes de Suprimento: integrando cadeias de suprimento num mundo globalizado. São Paulo: Atlas.

Corrêa, H.L.; Ellram, L.; Scavarda, A. and Copper, M. (2007) An Operations Management View of the Services and Goods Offering Mix. International Journal of Operations and Production Management, Vol. 27, No. 5. http://dx.doi.org/10.1108/01443570710742357

Dobberstein, N.; Neumann, C.-S. and Zils, M. (2005) Logistics in emerging markets. McKinsey Quarterly, February.

Elkington, J. (1997) Cannibals With Forks: The Triple Bottom Line of 21st Century Business. Oxford: Capstone.

Fisher, M. (1997) What is the right supply chain for your product. Harvard Business Review, Vol. 75, pp. 105-116.

Goldberg, R.A. and Yagan, J.D. (2007) McDonald's Corp.: Managing a Sustainable Supply Chain: Case study. Harvard Business School Publications. Product number 907414-PDFENG.

Gottfredson, M.; Puryear, R. and Phillips, S. (2005) Strategic Sourcing: From Periphery to the Core. Harvard Business Review, Vol. 83, No. 2, pp. 132-9. The Free Press.

Hayes, R.H. and Wheelwright, S. (1984) Restoring our competitive edge. New York:

Hill, T. (1985) Manufacturing strategy. Milton Keynes: U.K.Open University Press.

Johnston, R. (1994) Operations: From Factory to Service Management. International Journal of Service Industry Management, Vol. 5, No. 1, pp. 49-63. http://dx.doi. org/10.1108/09564239410051902

McKinsey. (2012) McKinsey Global Survey results: The challenges ahead for supply chains. Available: http://www.mckinseyquarterly.com/The_challenges_ahead_for_supply_ chains_McKinsey_Global_Survey_results_2706. Access: 16th October 2012.

Mik, Y.; Niemeyer, A. and Ruwadi, B. (2001) Building the supply chain of the future. McKinsey Quarterly.

Narayanan, V.G. and Raman, A. (2004) Aligning Incentives in Supply Chains. Harvard Business Review, Vol. 82, No. 11, pp. 94-102. 
Sheffi, Y. (2005) The Resilient Enterprise. MIT Press. London: Massachisetts.

Skinner, W. (1969) Manufacturing - the missing link in corporate strategy. Harvard Business Review, Vol. 47, No. 3, pp. 136-145.

Skinner, W. (1974) The focused factory. Harvard Business Review, pp. 113-122.

Taylor, F.W. (1911) The Principles of Scientific Management. New York: Harper Bros.

Tedlow, R.S. (2001) Seven Business Innovators and the Empires They Built. New York: HarperCollins.

Trent, R.J. and Monczka, R.M. (2005) Achieving Excellence in Global Sourcing. Sloan Management Review, Vol. 47, No. 1.

Utterback, J. (1994) Mastering the Dynamics of Innovation. Boston: Harvard Business School Press.

Womack, J. and Jones, D. (2003) Lean Thinking. The Free Press. New York: Simon \& Schuster.

\section{Biography}

Henrique Correa, Ph.D. (Warwick Business School, UK) is Professor of Operations Management at Rollins College, Winter Park, USA. Correa previously taught at the FGV Business School and at the University of São Paulo, Brazil. He has also served visiting appointments in Europe and the USA and consulted with various Fortune 500 companies. Correa has published extensively in academic journals and has authored and co-authored eight books and textbooks in operations management. He was the 2011-2012 sole recipient of the prestigious Rollins College Bornstein Award for Faculty Scholarship.

Contact: hcorrea@rollins.edu

\section{Article Info:}

Received: August, 2012

Accepted: October, 2012 